\title{
Comportamiento frente a la corrosión de uniones soldadas por fricción agitación de AA7075-T651: Evaluación galvánica
}

\section{Corrosion behavior of friction stir welds on AA7075-T651:Galvanic evaluation}

\author{
${ }^{1}$ Centro de Procesos Superficiales, INTI, Av. Gral. Paz 5445, San Martín, Argentina. \\ e-mail: hiperez@inti.gob.ar, berardo@inti.gob.ar \\ ${ }^{2}$ Grupo de Tecnología de la Soldadura, Centro de Mecánica, INTI. Av. Gral. Paz 5445, San Martín, Buenos Aires, Ar- \\ gentina. \\ e-mail: tufaro@inti.gob.ar \\ ${ }^{3}$ GTSyCM3, INTECIN, Facultad de Ingeniería, Universidad de Buenos Aires y CONICET. Av. Las Heras 2214, Buenos \\ Aires, Buenos Aires, Argentina. \\ e-mail: hsvobod@fi.uba.ar
}

\section{RESUMEN}

La soldadura por Fricción Agitación (FSW) es un proceso en estado sólido que ha revolucionado la soldadura de aleaciones de aluminio. La industria aeronáutica y otras han incorporado este proceso para la fabricación de elementos estructurales, empleando aleaciones de alta resistencia como las conocidas AA7075 o AA2024.

Durante la FSW se forman, como consecuencia del ciclo termomecánico aplicado, distintas zonas entre las que se encuentran la zona agitada (WN), la zona termomecánicamente afectada (TMAZ), y la zona térmicamente afectada (HAZ). Cada una de ellas presenta características metalúrgicas diferenciadas, por lo que la resistencia a la corrosión podría verse afectada.

El objetivo de este trabajo fue estudiar el comportamiento frente a la corrosión de uniones soldadas por FSW en AA7075-T651. Para ello, se soldaron probetas de (150x150) mm de AA7075-T651 por FSW con una velocidad de rotación de $680 \mathrm{rpm}$ y dos velocidades de avance: $51 \mathrm{~mm} / \mathrm{min}$ y $206 \mathrm{~mm} / \mathrm{min}$.

Se realizó una caracterización microestructural de las diferentes zonas de la soldadura, y se analizó el comportamiento galvánico a través de ensayos de inmersión en una solución de 3,5\% de $\mathrm{NaCl}$ sin eliminación de oxígeno y de ensayos de contacto con gel al 3\% de agar, 3,5\% de $\mathrm{NaCl}$ y solución de indicador de $\mathrm{pH}$ universal. Se extrajeron muestras para la caracterización microestructural del ataque.

Se observó la presencia de un ataque localizado en la interfase TMAZ-HAZ caliente. La caracterización a través de SEM indicó un ataque intergranular de gran envergadura, con la coalescencia de diversos ataques. Se observó una preponderancia del ataque en el lado de retroceso de soldadura.

Palabras clave: Corrosión, FSW, soldadura, galvánico.

\section{ABSTRACT}

Friction Stir Welding (FSW) is a novel solid-phase welding process, which has proved to have a great potential for the realization of welded joints in materials with poor weldability such as heat-treatable aluminum alloys. The aerospace industry has incorporated this process for the manufacture of structural elements, using known high strength alloys such as AA7075 or AA2024.

During FSW, different areas are formed due to the thermomechanical cycle applied, which have been named: the stirred zone (WN), the thermo-mechanically affected zone (TMAZ) and the heat affected zone (HAZ). Each zone presents different metallurgical characteristics, so the corrosion resistance could be affected. This is a relevant aspect for multiple applications and the implications are still not clear.

The aim of this work was to study the corrosion behavior of FSWed joints on AA7075-T651. For this 
purpose, samples of $150 \times 150 \mathrm{~mm}$ have been welded with a rotation speed of $680 \mathrm{rpm}$ and two welding speeds: 51 and $206 \mathrm{~cm} / \mathrm{min}$.

A microstructural characterization of the different zones of the welds was carried out, and the galvanic behavior of the specimens was analyzed through inmersion tests in a solution of 3,5\% $\mathrm{NaCl}$ without oxygen removal; and agar gel test, by contacting the specimen with a gel membrane prepared with 3\% agar, 3.5\% $\mathrm{NaCl}$ and $\mathrm{pH}$ universal indicator solution. Samples for macro and microstructural characterization were extracted.

The results showed the presence of a localized attack at the TMAZ-hot HAZ interface. The characterization through SEM indicated a major intergranular attack, with the coalescence of several attacks. In turn, preponderance in the attack was observed on the retreating side of the weld.

Keywords: Corrosion, FSW, Weld, galvanic.

\section{INTRODUCCIÓN}

Las aleaciones de aluminio se caracterizan por una amplia variedad en composición y gran versatilidad en su aplicación, lo que explica su gran difusión en variadas industrias, como la aeronáutica y aeroespacial, para la fabricación de componentes estructurales. Estas aleaciones, tradicionalmente soldadas por procesos de fusión convencionales, suelen presentar problemas como la fisuración en caliente y porosidad que, en el caso de la aviación, han limitado la aplicación del aluminio sólo a componentes remachados. En particular, la serie 7xxx, de muy alta resistencia mecánica, se considera no-soldable por dichos procesos debido a las bajas propiedades mecánicas de la unión en comparación con el material base [1].

Los principales aleantes presentes en la aleación 7075 son el $\mathrm{Zn}, \mathrm{Mg}$ y $\mathrm{Cu}$, los cuales forman precipitados endurecedores, en particular el $\mathrm{MgZn}_{2}$ y el $\mathrm{MgAlCu}$, durante el tratamiento térmico de envejecimiento $[5,8,9]$.

La designación T651 de esta aleación indica que el tratamiento térmico aplicado es un tratamiento de solubilización a $465{ }^{\circ} \mathrm{C}$, templado y luego un envejecido a $120^{\circ} \mathrm{C}$ por $24 \mathrm{~h}$, de manera de alcanzar la dureza máxima. El endurecimiento producido se debe a la formación tanto de precipitados de tamaños manométricos de $\mathrm{MgZn} 2-\mathrm{MgAlCu}$, denominada fase $\eta_{0}$, así como de zonas GP, donde los aleantes que luego pueden precipitar se enriquecen dentro de la red cristalina de la matriz metálica $[7,8]$.

La Soldadura por Fricción Agitación, en inglés Friction Stir Welding (FSW), fue desarrollada en The Welding Institute (TWI) en 1991, como técnica de unión en estado sólido. Una herramienta no-consumible, que rota sobre su eje, avanza sobre la superficie de contacto de las dos piezas a unir, generando el calor y flujo de material necesario para producir la unión. El calor se logra por la fricción entre la herramienta y la pieza, así como la deformación plástica del material [1,2]. Un esquema de dicho proceso se puede observar en la Figura 1.

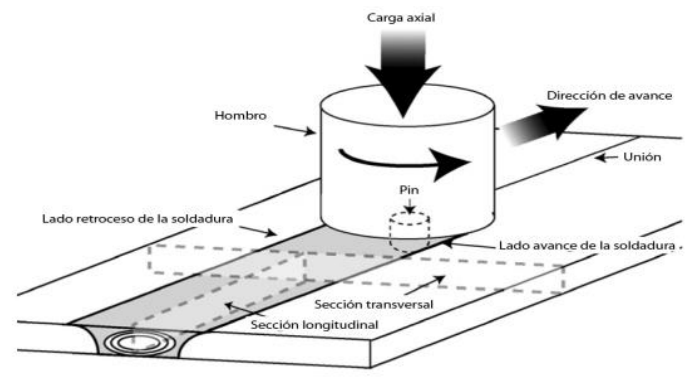

Figura 1: Esquema del proceso de soldadura por fricción agitación [1].

La FSW puede ser utilizada para unir piezas de la mayoría de las aleaciones de aluminio. En comparación con los procesos convencionales de fusión, consume menos energía, es decir, posee una mayor eficiencia energética. El ambiente en el que se desarrolla el proceso es más seguro ya que no hay presencia de efluentes gaseosos. Además, no requiere material de aporte ni preparación de junta. Sólo requiere, a diferencia de los métodos tradicionales, una sujeción más rígida debido a las elevadas fuerzas involucradas en el proceso [1,2].

En la unión soldada obtenida mediante este proceso se pueden distinguir, sobre un corte transversal, 
tres zonas diferenciadas según sus características microestructurales: zona agitada (WN), zona termomecánicamente afectada (TMAZ) y zona térmicamente afectada (HAZ). En el WN se produce la agitación del material alrededor del pin de la herramienta, generando una fuerte deformación plástica en caliente lo que produce la recristalización del material en dicha zona, y una disolución de los precipitados preexistentes, así como su reprecipitación, proceso que depende del ciclo térmico. En la TMAZ se tiene una deformación sin alcanzar la recristalización, mientras que en la HAZ se produce la disolución parcial y sobreenvejecido de los precipitados $[1,2]$.

Desde el punto de vista químico, el aluminio es un metal altamente reactivo y, si se lo compara con otros metales estructurales, solo es superado en reactividad por el magnesio y el berilio. A pesar de esto, la resistencia a la corrosión del aluminio suele considerarse alta, debido a que en exposición atmosférica se forma una película superficial de óxido de aluminio compacta, fuertemente adherida al metal base, que disminuye drásticamente la velocidad de corrosión del metal. Este estado de la superficie se denomina pasividad [3].

En el caso de las aleaciones de aluminio, la respuesta de las mismas frente a los agentes corrosivos depende de la microestructura de la aleación. Los diferentes tipos de compuestos intermetálicos precipitados afectan el comportamiento de la aleación tanto por sus características electroquímicas intrínsecas, como por su distribución espacial en la matriz metálica [3].

En este contexto, la aleación AA7075 se presenta como muy susceptible a diferentes tipos de ataques de tipo localizado, como el picado, corrosión intergranular, corrosión exfoliación, así como corrosión bajo tensiones [3].

En el caso de uniones soldadas de la aleación AA7075, se ha reportado que las zonas HAZ, TMAZ y WN presentan una mayor susceptibilidad a la corrosión que el material base [4,5].

Sin embargo es escasa la información disponible, quedando aún muchos aspectos por resolver. Por otro lado, los parámetros de soldadura afectan la cantidad de calor aportado y por lo tanto la degradación microestructural impuesta, pudiendo así afectar la resistencia a la corrosión de la unión soldada. En ese sentido, en un trabajo anterior [6] los autores evaluaron el comportamiento electroquímico de las diferentes zonas de las uniones soldadas encontrando un aumento de la susceptibilidad a la corrosión localizada.

El objetivo del presente trabajo fue estudiar el comportamiento frente a la corrosión desde el punto de vista galvánico de uniones soldadas por FSW de una aleación de aluminio AA7075-T651.

\section{MATERIALES Y MÉTODOS}

El material base utilizado en este trabajo fue una chapa de aleación de aluminio AA 7075-T651, de $4 \mathrm{~mm}$ de espesor. Se soldaron a tope dos placas de $150 \mathrm{~mm}$ de largo y $75 \mathrm{~mm}$ de ancho, empleando el sistema de FSW observado en la Figura 2. Las soldaduras fueron realizadas usando una herramienta con un pin cónico liso y un hombro cóncavo. El ángulo de inclinación fue de 1,5. Se evaluaron dos velocidades de avance: 51 y 206 $\mathrm{mm} / \mathrm{min}$, con una velocidad de rotación a $680 \mathrm{rpm}$.

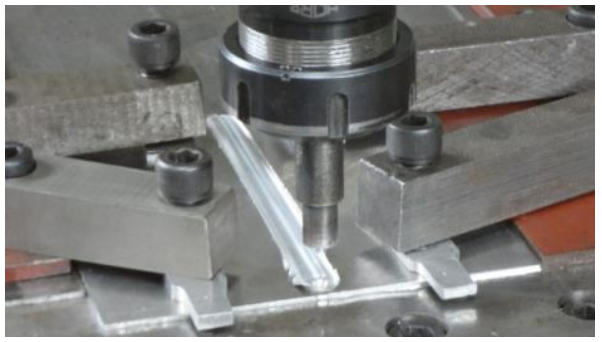

Figura 2: Ejecución de soldaduras por fricción agitación.

Para cada unión soldada, se obtuvieron tres ciclos térmicos durante la soldadura, correspondientes a termocuplas ubicadas a 7,5 mm, 14,5 $\mathrm{mm}$ y $21,5 \mathrm{~mm}$ de la línea de soldadura, en la mitad de la longitud de la probeta.

Debido a que se trata de una aleación termotratable, el tiempo posterior a la soldadura es un aspecto relevante. Las probetas analizadas en el presente trabajo tienen un tiempo de envejecimiento de 1330 días \pm 60 días.

A partir de cortes transversales extraídos de las probetas soldadas, se obtuvieron perfiles de microdureza Vickers sobre dos líneas, una a mitad del espesor de la chapa y otra a $300 \mu \mathrm{m}$ de la superficie 
libre de la probeta (cara).

Se realizó una caracterización de la distribución de precipitados en las diferentes zonas de la unión soldada por medio de microscopio electrónico de barrido (SEM), marca FEI modelo Quanta 250FEG, revelando la microestructura por medio de dos reactivos: solución de Keller (15 s de inmersión) y $\mathrm{H}_{3} \mathrm{PO}_{4}$ al $10 \%\left(5 \mathrm{~min}\right.$ a $\left.50^{\circ} \mathrm{C}\right)$.

Se analizó el comportamiento frente a la corrosión a través de ensayos de inmersión de las probetas en una solución de 3,5\% de $\mathrm{NaCl}$ sin eliminación de oxígeno, durante 60 minutos. Luego de dicho periodo, las probetas se evaluaron superficialmente a través de macrografías y SEM de las diferentes zonas de la unión soldada.

A su vez, se realizó un ensayo de corrosión de la superficie metálica en contacto con gel al 3\% de agar, 3,5\% de $\mathrm{NaCl}$ y solución de indicador de $\mathrm{pH}$ universal. Este ensayo permite observar visualmente los procesos corrosivos que se dan en las diferentes zonas de la soldadura, en función del $\mathrm{pH}$ desarrollado en cada una de ellas.

Ambos ensayos se realizaron sobre la superficie libre (cara) de la probeta soldada, en una sección de $(80 \times 25) \mathrm{mm}$, ubicando la línea central de la soldadura (LS) en la mitad de la longitud de la muestra. Dicha superficie se preparó progresivamente hasta un pulido con alúmina de $1 \mu \mathrm{m}$.

\section{RESULTADOS}

En la Tabla 1 se muestra la composición química determinada para el material de estudio, obtenida mediante espectrometría de emisión optica. Los elementos aleantes se encuentran dentro de lo especificado para este material [4].

Tabla 1: Composición química del AA7075-T651.

\begin{tabular}{l|l|l|l|l|l|l|l|l}
\hline ELEMENTO & $\mathbf{S i}$ & $\mathbf{F e}$ & $\mathbf{C u}$ & $\mathbf{M n}$ & $\mathbf{M g}$ & $\mathbf{C r}$ & $\mathbf{Z n}$ & $\mathbf{Z r}$ \\
\hline$\%(\mathrm{~m} / \mathrm{m})$ & 0,07 & 0,2 & 1,67 & 0,05 & 2,69 & 0,20 & 6,16 & 0,021 \\
\hline
\end{tabular}

En la Figura 3 se puede observar los ciclos térmicos registrados a las diferentes distancias para ambas probetas. Puede verse que al aumentar la velocidad de avance, las temperaturas máximas disminuyen y los gradientes de temperatura son más acusados, ya que el calor aportado es función del cociente entre la potencia neta aportada y dicha velocidad. En este sentido, la degradación microestructural asociada al ciclo térmico de la soldadura será diferente para cada caso.

En las Figuras 4 y 5 se muestran los perfiles de dureza medidos en las probetas 680-51 y 680-206.
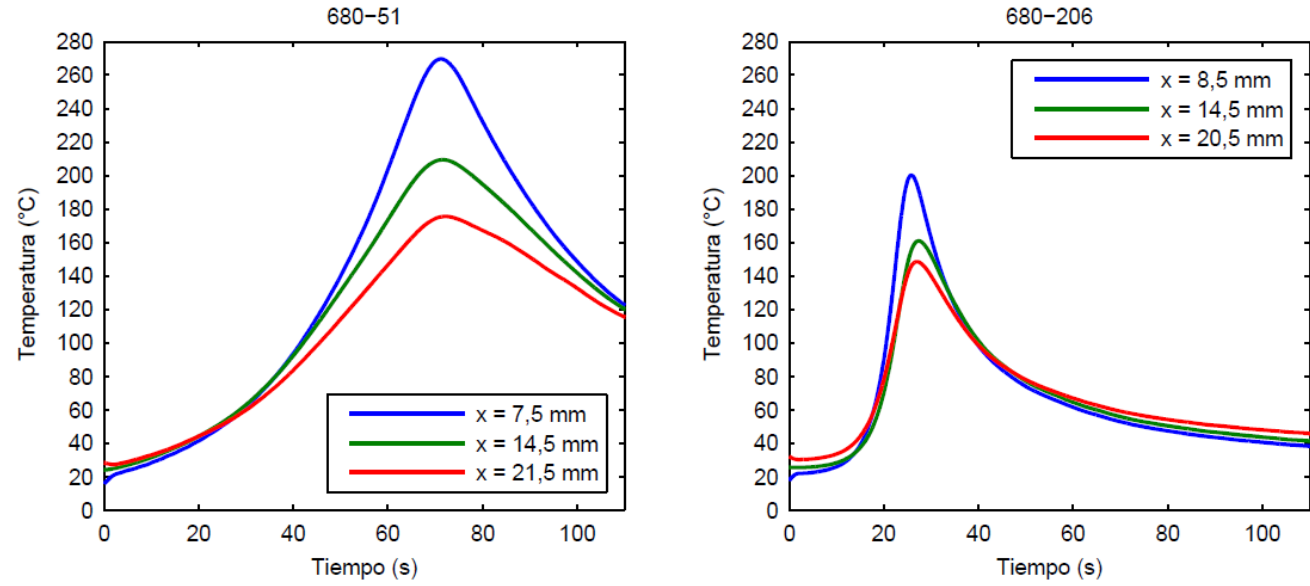

Figura 3: Ciclos térmicos de las uniones soldadas. 


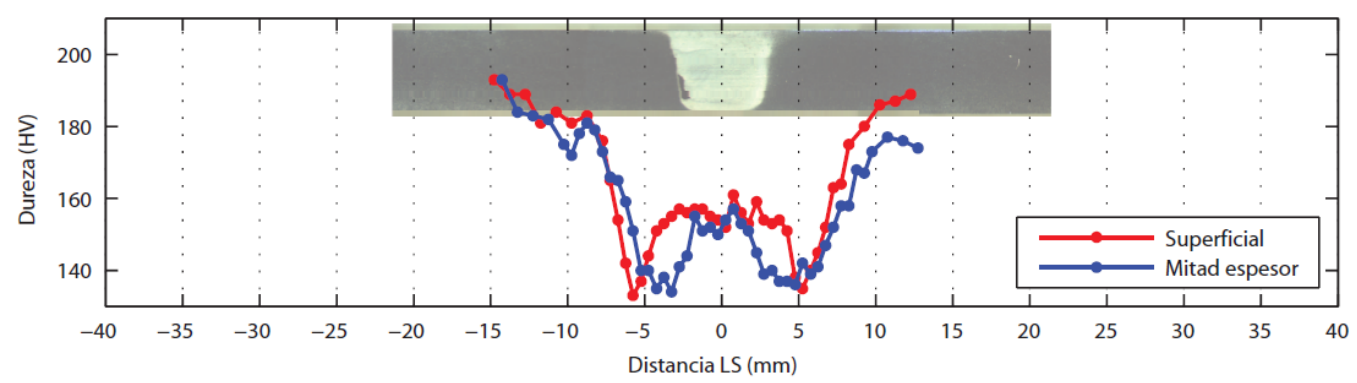

Figura 4: Perfiles de microdureza Vickers, probeta 680-51.

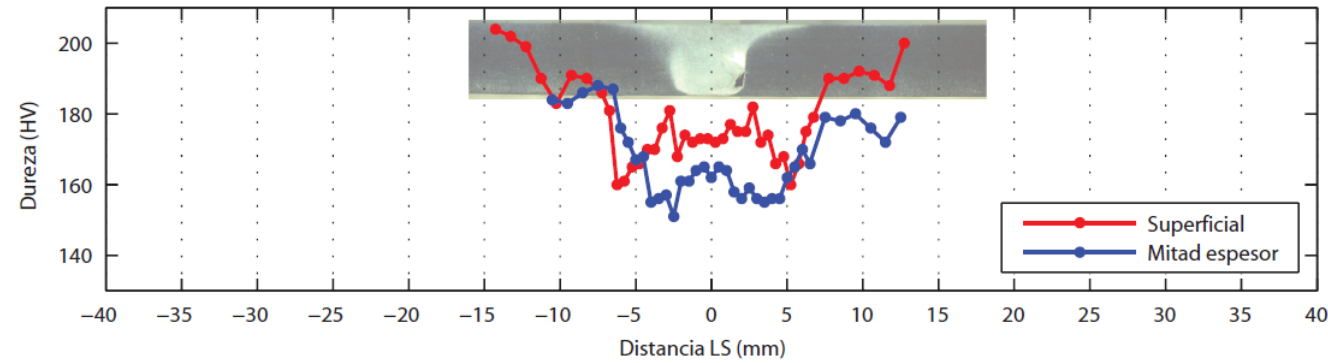

Figura 5: Perfiles de microdureza Vickers, probeta 680-206.

En ambos casos puede verse una disminución de la microdureza desde el MB hacia el WN, alcanzando un mínimo en la HAZ. Este descenso de la microdureza se debe a la disolución de las zonas GP y $\eta_{0}$ debido al ciclo térmico en las zonas afectadas por el calor. En la probeta 680-51, que posee un ciclo térmico más caliente, se observa una disminución de la dureza más acentuada que el observado en la 680-206. El ascenso relativo en la zona del WN se debe a la disminución del tamaño de grano característico de dicha zona, por efecto de la recristalización $[9,10]$. Las mediciones realizadas en la zona cercana a la superficie son similares aunque los valores de microdureza alcanzados son en general algo mayores que en la zona media del espesor.

En la figura 6 se muestra las imágenes obtenidas por SEM de la zona del WN. Se puede observar la presencia de precipitados de tamaños del orden de los cientos de nanómetros.
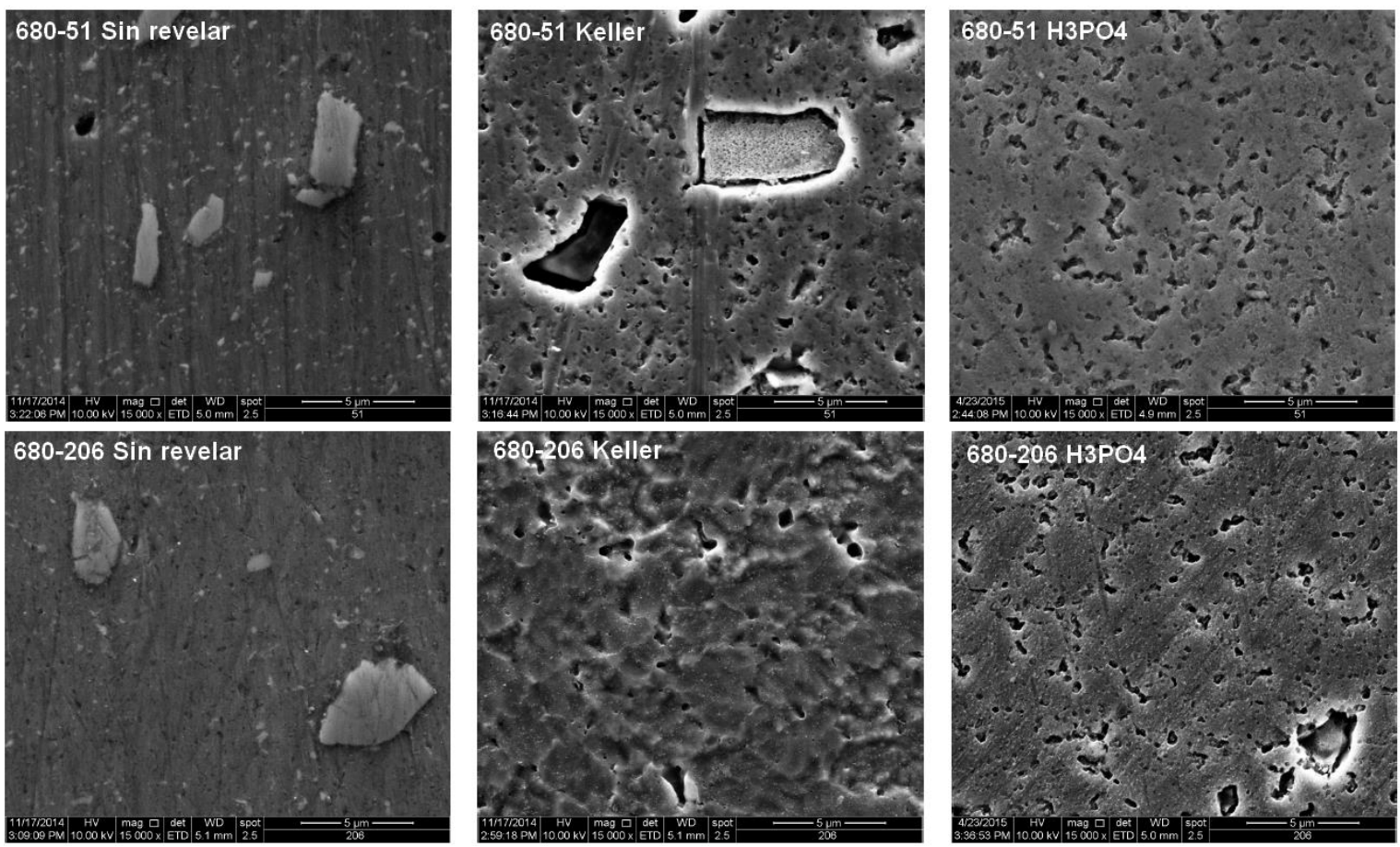

Figura 6: Imagenes SEM, Weld nugget, 15000x. 
Analizando las imágenes por medio del programa ImageJ, se caracterizó la densidad de partículas y su tamaño promedio (Tabla 2). No se observa una diferenciación clara del borde de grano en la probeta 680-51, mientras que en la probeta 680-206 se puede llegar a apreciar algunos bordes de grano, pero no es lo suficientemente claro como para aplicar algún método normalizado. Medidas puntuales indican un tamaño de entre 2 $\mu \mathrm{m}$ y $5 \mu \mathrm{m}$, lo cual es consistente con lo reportado en la literatura [11,12].

Tabla 2: Caracterización de los precipitados del WN.

\begin{tabular}{c|c|c}
\hline PROBETA & $\begin{array}{c}\text { Densidad de partículas } \\
\left(\text { partículas } / \mu \mathrm{m}^{2}\right)\end{array}$ & $\begin{array}{c}\text { Diámetro promedio } \\
(\mu \mathrm{m})\end{array}$ \\
\hline $\mathbf{6 8 0 - 5 1}$ & $0,9 \pm 0,2$ & $0,20 \pm 0,02$ \\
\hline $\mathbf{6 8 0 - 2 0 6}$ & $0,6 \pm 0,15$ & $0,21 \pm 0,02$ \\
\hline
\end{tabular}

En la interfase TMAZ-HAZ caliente (Figura 7) se observa la presencia de una disolución de tipo picado, localizada casi exclusivamente en los bordes de grano. Dicho ataque es más marcado en la probeta 680-51, y su morfología se asemeja a la disolución presente en el WN, lo que sería un indicio de que los precipitados en dicha zona también estén ubicados en borde de grano.
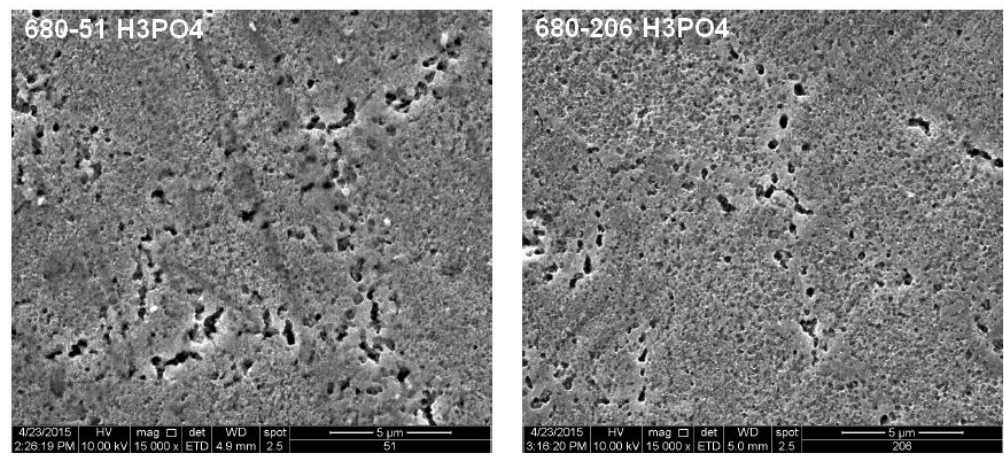

Figura 7: Imágenes SEM, TMAZ-HAZ caliente, 15000x.

En el HAZ, el revelado por ácido fosfórico (Figura 8) muestra un ataque por disolución de los precipitados, tanto en borde como en seno de grano, siendo considerablemente mayor en el borde. El ataque es mayor en la probeta 680-51, se observa que el ataque en borde de grano es discontinuo y de un tamaño mayor que la probeta 680-206, donde se observa un ataque continuo alrededor del borde de grano. El ataque del material base es similar al obtenido en la HAZ de la probeta 680-206.
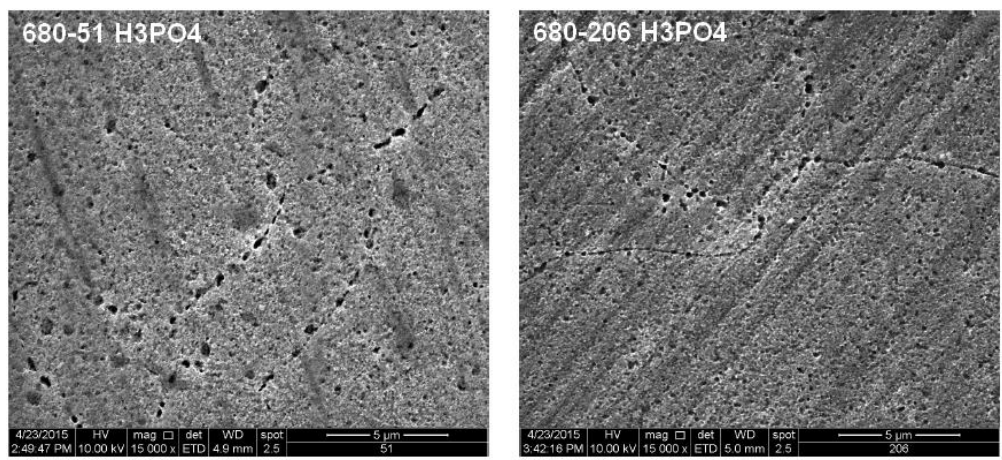

Figura 8: Imágenes SEM, HAZ, 15000x

En las Figuras 9 y 10, se pueden observar las macrografías obtenidas en la superficie libre de las probetas soldadas luego de ser sumergidas durante $60 \mathrm{~min}$ en la solución de ensayo. La línea roja indica la ubicación original de la línea de soldadura. Se puede apreciar la presencia de un ataque localizado de tipo 
picado en la superficie de la zona agitada, con un aumento de la densidad del picado en la interfase TMAZHAZ caliente, para ambas condiciones de soldadura.

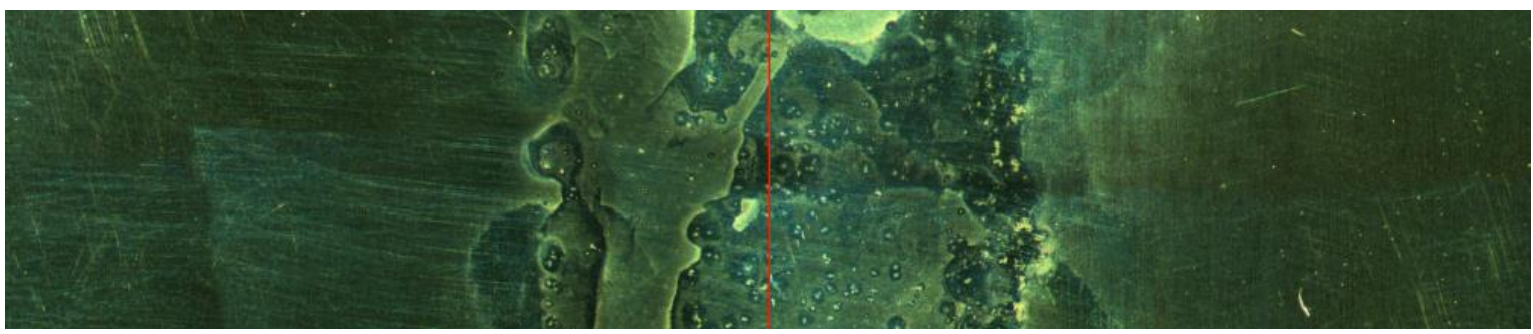

Figura 9: Macrografía luego de ensayo de corrosión por inmersión, probeta 680-51

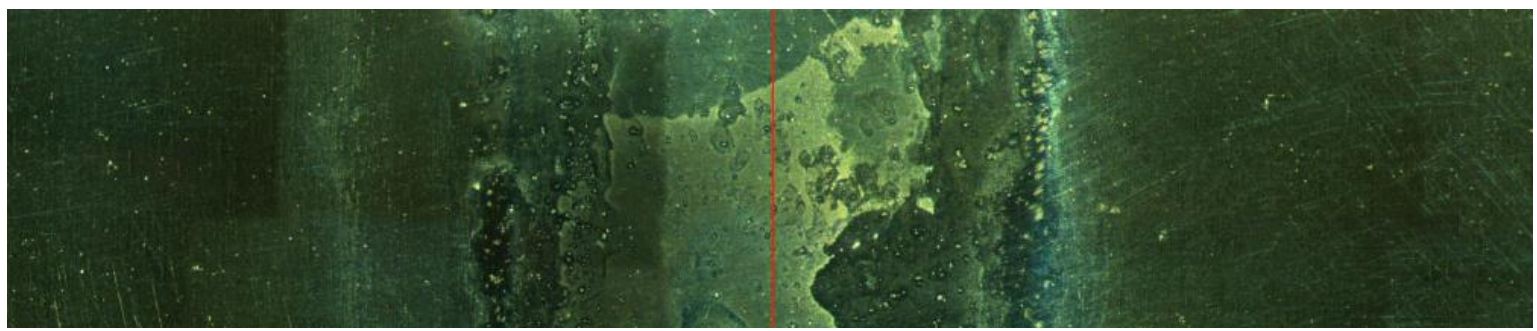

Figura 10: Macrografía luego de ensayo de corrosión por inmersión, probeta 680-206

En las Figuras 11 y 12 se pueden observar las superficies de las zona del weld nugget en las probetas 680-51 y 680-206, respectivamente.
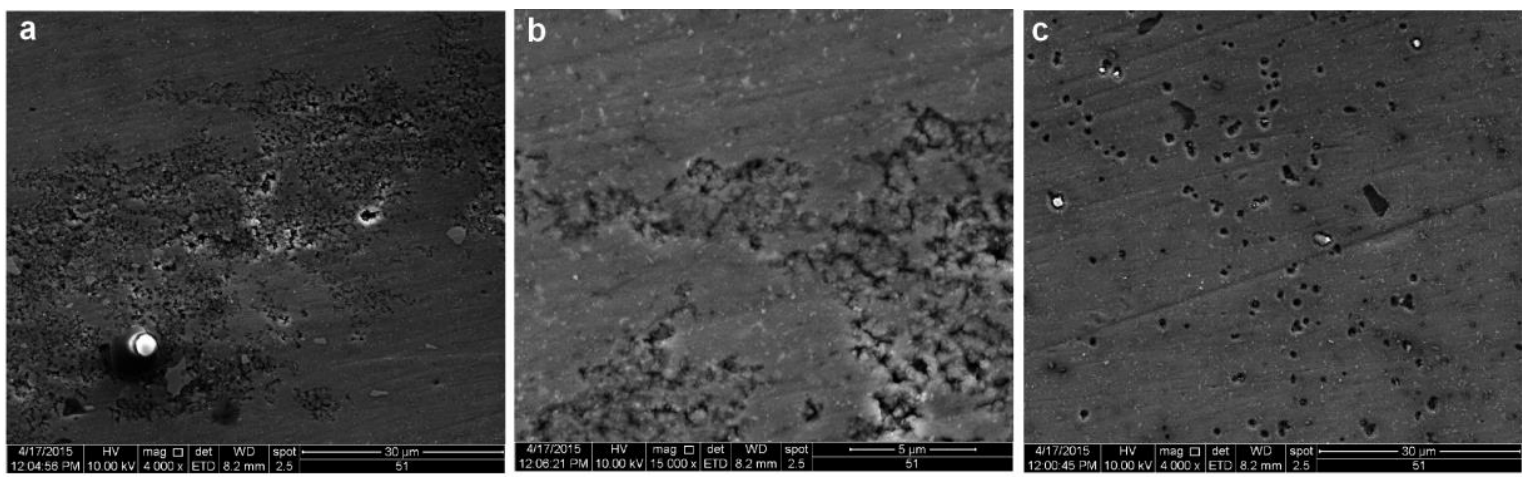

Figura 11: Imagenes SEM, probeta 680-51, weld nugget. a) 4000x, b) 15000x y c) 4000x
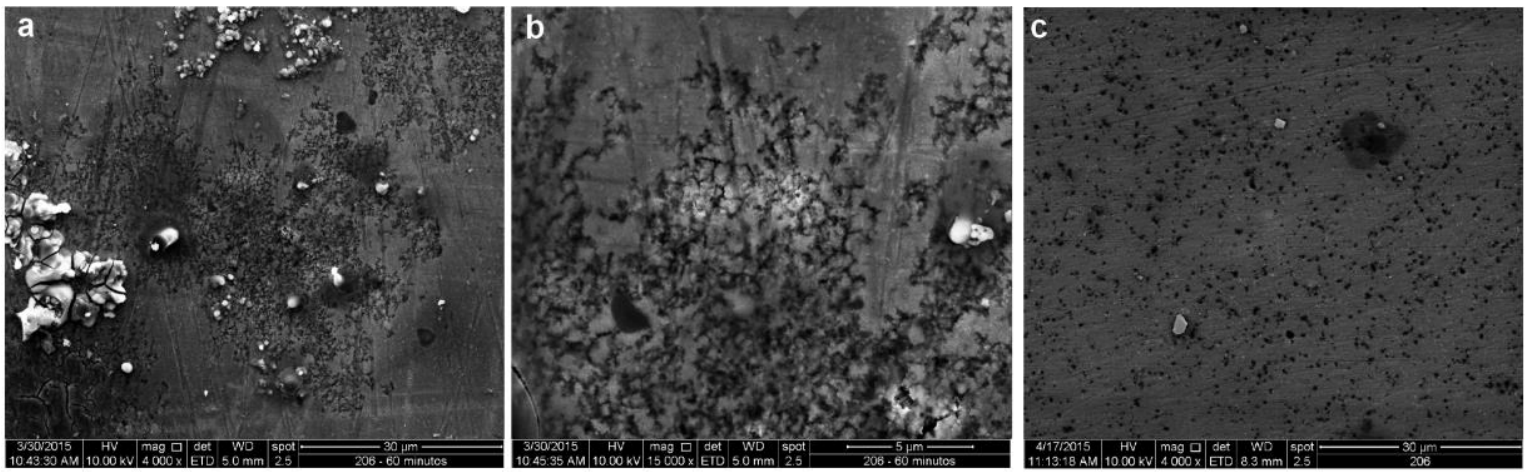

Figura 12: Imagenes SEM, probeta 680-206, weld nugget. a) 4000x, b) 15000x y c) 4000x

En ambas probetas se pueden distinguir dos tipos de ataques, una zona donde se observa un ataque de tipo picado distribuido (Figura 11c y 12c), y otra zona en donde el ataque se encuentra concentrado (Figuras 11a, 11b, 12a y 12b), en lo que pareciera ser la disolución de los precipitados y agrupamiento de las 
oquedades. En el caso de la probeta 680-206, dicho ataque es visiblemente intergranular, mientras que en la 680-51 no se puede apreciar con claridad.

En las Figuras 13 y 14 se pueden observar las superficies de las zonas TMAZ-HAZ caliente en las probetas 680-51 y 680-206, respectivamente.
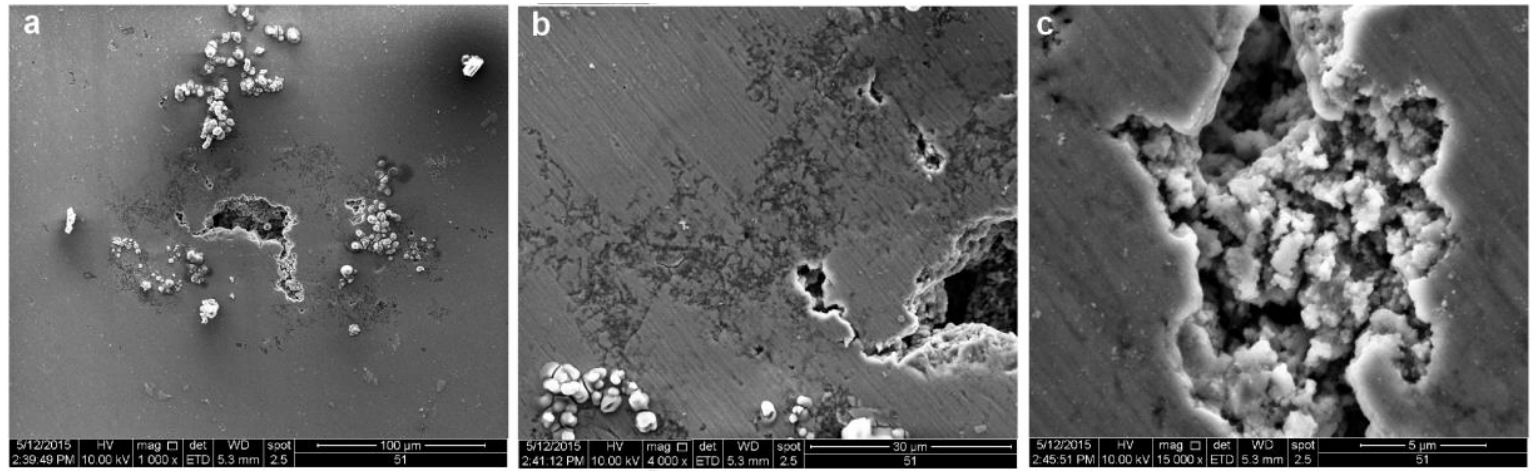

Figura 13: Imagenes SEM, probeta 680-51, TMAZ-HAZ caliente. a) 1000x, b) 4000x y c) 15000x
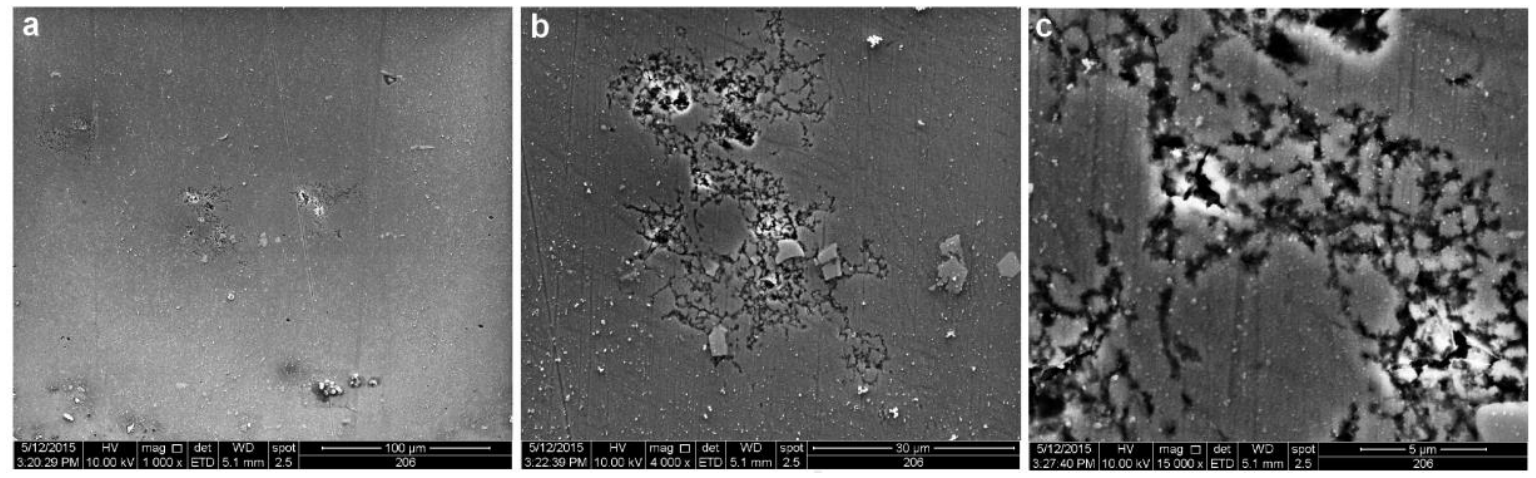

Figura 14: Imagenes SEM, probeta 680-206, TMAZ-HAZ caliente. a) 1000x, b) 4000x y c) 15000x

Se puede observar un ataque que parece ser por disolución de precipitados en borde de grano. El ataque es lo suficientemente intenso como para coalescer y formar oquedades de gran tamaño.

En la Figura 15a y 15b se puede apreciar las superficies de la zona HAZ en las probetas 680-51 y 680206, respectivamente. En la Figura 15 c se puede observar la superficie del material base.
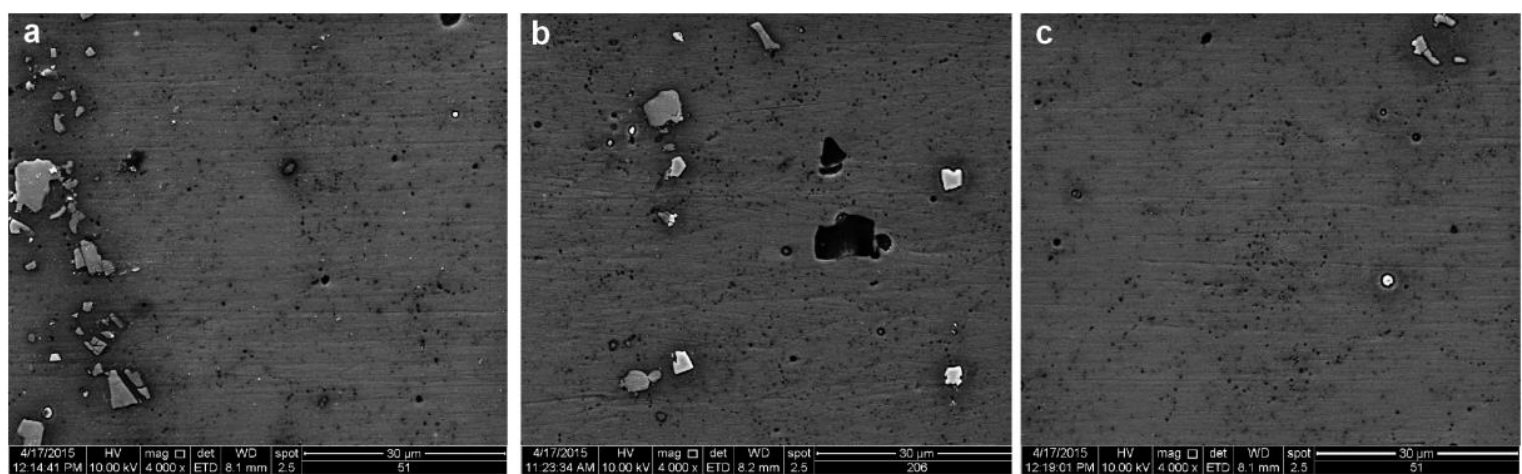

Figura 15: Imagenes SEM: a) HAZ, 4000x 680-51, b) HAZ, 4000x 680-206 y c) Material base

En ambas probetas en la zona HAZ se observa un ataque de tipo picado a lo largo de lo que parece ser el borde de granos. De igual manera, en el material base, se observa la misma morfología de ataque.

En la Figura 16 se muestran las fotografías de la película de agar en contacto con la superficie libre de la unión soldada, obtenidas a las 0, 0,5, 1, 2, 3, 4, 5 y 6,6 horas, así como de la película de agar al finalizar el ensayo, para ambas probetas. En la Figura 17 se esquematiza las diferentes zonas de igual pH y su evolución en el tiempo. 

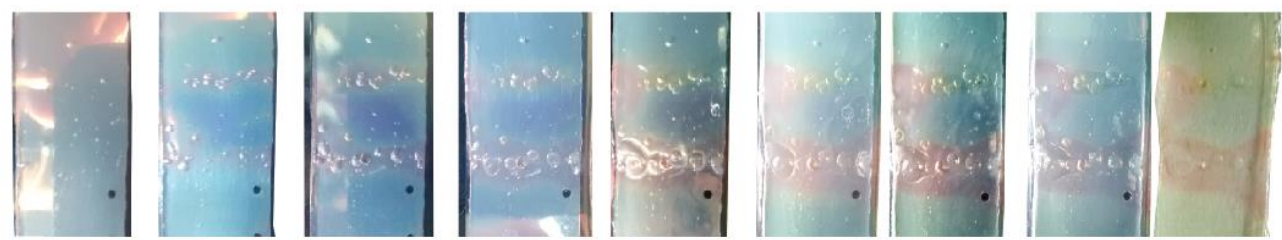

$680-51$
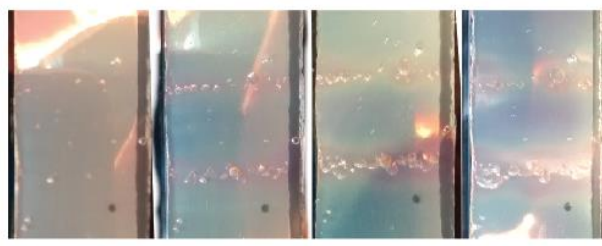

$\mathrm{Oh}$

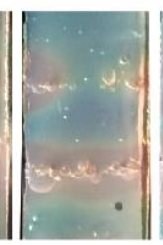

$3 \mathrm{~h}$

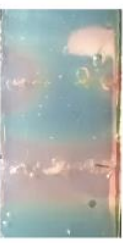

$4 \mathrm{~h}$

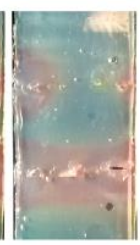

$5 \mathrm{~h} \quad 6,6 \mathrm{~h}$

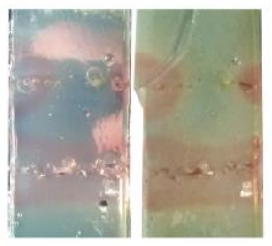

$680-206$

Figura 16: Fotografías de las uniones soldadas a diferentes tiempos de exposición
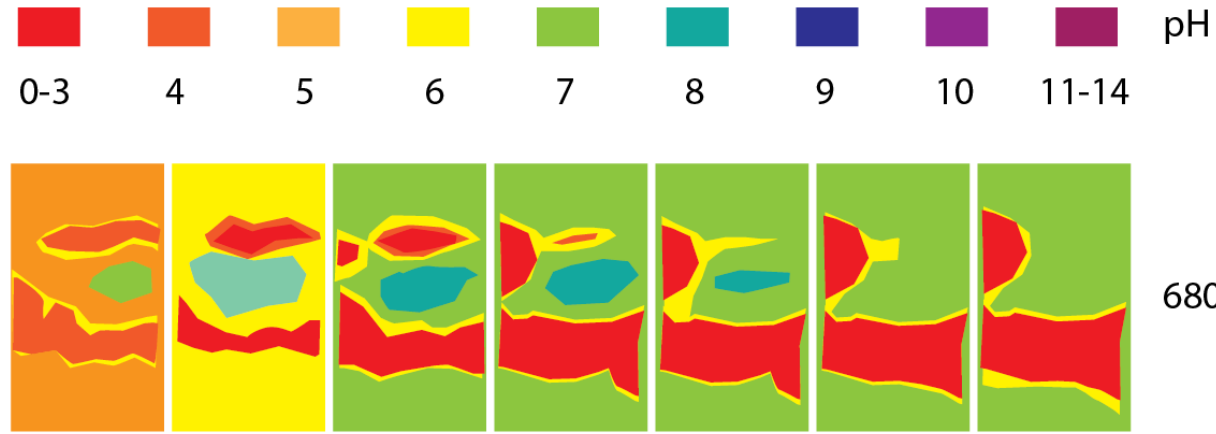

$680-51$
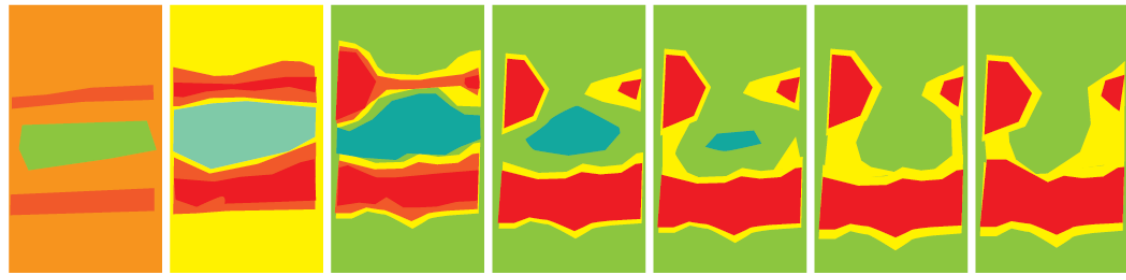

680-206

$0,5 \mathrm{~h}$

$1 \mathrm{~h}$

$2 \mathrm{~h}$

$3 \mathrm{~h}$

$4 \mathrm{~h}$

$5 \mathrm{~h}$

$6,6 \mathrm{~h}$

Figura 17: Esquema aproximado de las zonas de igual $\mathrm{pH}$

El pH inicial de la película de agar es de 5. A los 30 minutos se observa la formación de dos zonas donde el pH disminuye, ubicadas a aproximadamente $5 \mathrm{~mm}$ de la línea de soldadura. El descenso del pH en dichas zonas está asociado a procesos anódicos de disolución. catódicos

En la zona del WN se evidencia un aumento del $\mathrm{pH}$, lo que indica una predominancia de procesos

A la hora de exposición se observa un aumento del $\mathrm{pH}$ en la superficie de la película. En la zona de interfase WN-TMAZ/HAZ se sostiene la disminución del $\mathrm{pH}$, mientras que en el WN el pH sigue aumentando.

Al avanzar el tiempo de exposición, el pH de la superficie alejada de la zona de soldadura se estabiliza en un valor cercano a 7. La zona de interfase WN-TMAZ/HAZ ubicada en el lado de avance de la soldadura tiende a disminuir su acidez, mientras el área ácida en la zona ubicada en el lado retroceso va aumentando su tamaño. El área básica ubicada en el WN disminuye hasta desaparecer a las 5 hs de exposición. Ambas condiciones de soldadura mostraron resultados similares.

\section{DISCUSIÓN}

En función de lo observado en la evaluación microestructural de las diferentes zonas de las soldaduras, se 
pudo establecer la existencia de precipitados que varían su densidad y su tamaño dependiendo del ciclo térmico de cada zona. De todos los compuestos intermetálicos presentes en la aleación, el único capaz de precipitar en el rango de temperaturas al que fueron sometidas las uniones soldadas, es el $\mathrm{MgZn}_{2} / \mathrm{AlMgCu}$ (fase $\eta$ ) $[5,8,9]$.

Un esquema propuesto de precipitación en base a las observaciones realizadas de cada una de las zonas se esquematiza en la figura 18.

- Material base: Fase $\eta$ distribuida en forma continua en borde de grano. Zonas G-P y $\eta_{0}$ distribuidas coherentemente en la matriz. Relación entre precipitados borde de grano y precipitados en seno de grano $\left(\mathrm{P}_{\text {pdosborde }} / \mathrm{P}_{\text {pdosseno }}\right)$ baja.

- HAZ: Fase $\eta$ distribuida en forma de partículas a lo largo del borde de grano. Zonas G-P y partículas $\eta_{0}$ y $\eta$ finas distribuidas en el seno del grano. Relación $\mathrm{P}_{\text {pdosborde }} / \mathrm{P}_{\text {pdosseno }}$ baja.

- TMAZ: Granos deformados no recristalizados. Fase $\eta$ distribuida en forma de partículas de gran tamaño a lo largo del borde de grano. Zonas G-P y partículas $\eta_{0}$ y $\eta$ intermedias distribuidas en el seno del grano. Relación $\mathrm{P}_{\text {pdosborde }} / \mathrm{P}_{\text {pdosseno }}$ intermedia.

- Weld nugget: Grano recristalizado. Fase $\eta$ distribuida en forma de partículas de gran tamaño a lo largo del borde de grano. Zonas G-P y partículas $\eta_{0}$ y $\eta$ intermedias distribuidas en el seno del grano. Relación $\mathrm{P}_{\text {pdosborde }} / \mathrm{P}_{\text {pdosseno }}$ alta.

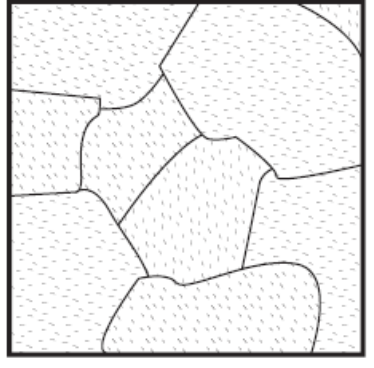

Material Base

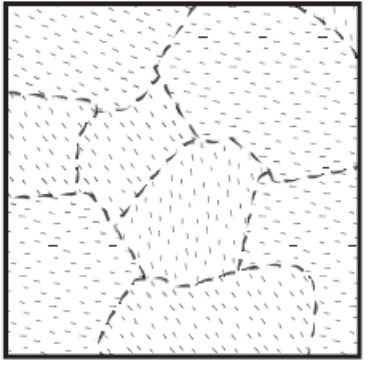

HAZ

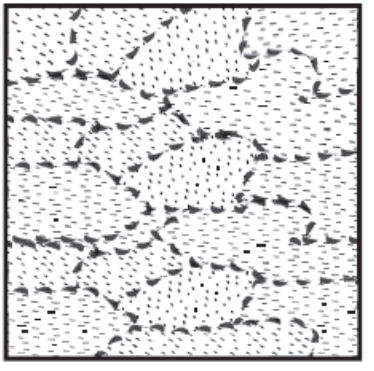

TMAZ

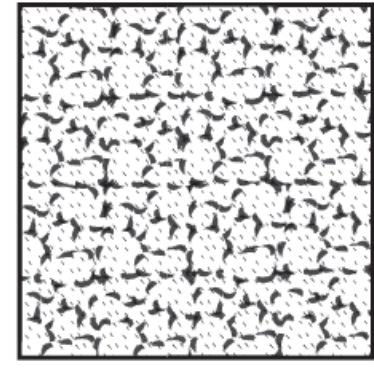

Nugget

Figura 18: Esquema de las microestructuras de la matriz y los precipitados de la fase $\eta\left(\mathrm{MgZn}_{2} / \mathrm{AlCuMg}\right)$

Evaluando los resultados de los ensayos de corrosión, es interesante notar que el ataque localizado observado en la zona de la interfase TMAZ-HAZ caliente en los ensayos de inmersión no se ve reflejado en un cambio determinante en los parámetros electroquímicos medidos en un trabajo anterior sobre la misma aleación en las mismas condiciones de unión ([6], ver Tabla 3), en donde se observa un descenso constante del potencial de corrosión y de picado desde el material base hasta llegar a un mínimo en el WN. A su vez, el ensayo de gel de agar indica que más allá de la posible susceptibilidad de cada zona inherente a la microestructura, existe un efecto galvánico que magnifica el daño.

Tabla 3: Potenciales de corrosión promedios del WN y del material base en las uniones soldadas [6]

\begin{tabular}{c|c|c|c|c|c|c|c}
\hline \multicolumn{2}{c|}{} & \multicolumn{3}{|c|}{$\mathbf{6 8 0 - 5 1}$} & \multicolumn{3}{c}{$680-206$} \\
\hline \multirow{3}{*}{$\begin{array}{c}\text { Ecorr } \\
(\mathbf{m V})\end{array}$} & Weld nugget & $-755,5$ & \pm & 7 & $-738,8$ & \pm & 10,4 \\
\cline { 2 - 8 } & $\begin{array}{c}\text { Material } \\
\text { base }\end{array}$ & -666 & \pm & 4 & -666 & \pm & 4 \\
\cline { 2 - 8 } & Diferencia & \multicolumn{3}{|c}{89,5} & \multicolumn{3}{|c}{72,8} \\
\hline
\end{tabular}

Teniendo en cuenta los potenciales de corrosión obtenidos por BIRBILIS et al. para algunas de las fases presentes en la aleación 7075 ([13], Ver Tabla 3) se puede apreciar que el $\mathrm{MgZn}_{2}$ tiene un potencial de corrosión más negativo que el potencial de corrosión de la matriz, por lo que tenderá a disolverse. A su vez, se corroe sin la formación de una película pasiva que disminuya la velocidad de reacción, lo que hace que los precipitados se corroan hasta su disolución completa sin ningún impedimento. 
Tabla 3: $\mathrm{E}_{\text {corr }} \mathrm{y} \mathrm{E}_{\mathrm{p}}$ de algunos componentes de la microestructura de la aleación 7075 [13]

\begin{tabular}{c|c|c|c|c|c|c}
\hline & \multicolumn{3}{|c|}{ Ecorr $(\mathrm{mV})$} & \multicolumn{3}{c}{ Ep (mV) } \\
\cline { 2 - 7 } & $0,01 \mathrm{M}$ & $0,1 \mathrm{M}$ & $0,6 \mathrm{M}$ & $0,01 \mathrm{M}$ & $0,1 \mathrm{M}$ & $0,6 \mathrm{M}$ \\
\hline Matriz 7075 & -699 & -799 & -812 & -633 & -736 & -768 \\
\hline AA 7075-T651 & -816 & -965 & -1180 & -684 & -739 & -810 \\
\hline $\mathrm{MgZn}_{2}$ & -1001 & -1029 & -1095 & - & - & - \\
\hline
\end{tabular}

La velocidad de reacción anódica sin embargo, está controlada por la corriente catódica disponible: a mayor relación de área catódica/anódica $\left(\mathrm{A}_{\mathrm{c}} / \mathrm{A}_{\mathrm{a}}\right)$, mayor será la velocidad de corrosión, y viceversa. En los ensayos de corrosión globales, existen grandes áreas predominantemente catódicas en la zona del material base, que contribuyen galvánicamente a disolver las zonas donde se encuentren expuestos los precipitados de $\mathrm{MgZn}_{2}$.

En el material base, este intermetálico se encuentra en forma de fase $\eta$ en el borde de grano, y disperso en el seno del grano como zonas G-P y fase $\eta_{0}$. La relación $A_{c} / A_{a}$ en esta zona es muy alta, por lo que es de esperar que la reacción de corrosión de las partículas anódicas está solo limitada por la velocidad de disolución anódica (o en un caso extremo, por la completa disolución de la partícula anódica), generando un excedente de corriente catódica.

Este exceso de corriente se redirige hacia una zona que sea capaz de consumirlo. Dicha zona es el WN-TMAZ-HAZ caliente, que posee una relación $\mathrm{A}_{\mathrm{c}} / \mathrm{A}_{\mathrm{a}}$ más baja debido a la presencia de precipitados de mayor tamaño. Sin embargo, las líneas de corriente se agrupan de manera de minimizar la caída de potencial; por ello, se concentran en la interfase TMAZ-HAZ caliente, ya que es la zona más cercana a la gran área catódica que representa el material base.

El WN, a pesar de ser tan susceptible como la interfase TMAZ-HAZ caliente, en las etapas iniciales tiene un comportamiento catódico, debido a estar encerrado entre dos zonas anódicas, a donde no llegan las líneas de corriente provenientes del material base.

La disolución de precipitado en la interfase se da hasta que el área anódica remanente en dicha zona sea baja, y el limitante nuevamente sea la reacción anódica, de manera que el proceso corrosivo galvánico avanza progresivamente hacia el interior del WN, donde aún existen precipitados sin disolver.

La relación entre daño corrosivo y parámetros de soldadura es débil, pero existe una correlación positiva entre calor aportado y susceptibilidad a la corrosión.

En ambos ensayos de corrosión se observó un ataque preferencial en el lado retroceso de la soldadura al aumentar el tiempo de exposición, lo cual no se pudo relacionar a una contraparte microestructural, por lo que deberá ser analizado con mayor detalle en trabajos posteriores.

\section{CONCLUSIONES}

Los ensayos de inmersión y de gel de agar efectuados en una sección de las uniones soldadas evaluadas permitieron caracterizar el efecto conjunto de la corrosión localizada con el efecto de corrosión galvánica en las diferentes zonas de la soldadura, con lo que se demostró que los efectos corrosivos en inmersión de la unión soldada tienen un fuerte componente galvánico, concentrando el ataque en las interfases TMAZ-HAZ caliente en los momentos iniciales, avanzando luego hacia el centro del WN.

\section{AGRADECIMIENTOS}

Los autores quieren agradecer al Instituto Nacional de Tecnología Industrial (INTI) y a la Universidad de Buenos Aires por el apoyo para este proyecto.

\section{BIBLIOGRAFÍA}

[1] MISHRA, R. MAHONEY, M., Friction Stir Welding and Processing, ASM International, 2007.

[2] NANDAN, R., DEBROY, T., BHADESHIA, H., "Recent advances in friction-stir welding--process, weldment structure and properties" Progress in Materials Science, Pergamon, 2008:53, 980-1023

[3] AMERICAN SOCIETY FOR METALS (ASM), ASM Handbook: Corrosion, v.13, ASM International, 1996. 
[4] BOUSQUET, E., POULON-QUINTIN, A., PUIGGALI, M., DEVOS, O., TOUZET, M., "Relationship between microstructure, microhardness and corrosion sensitivity of an AA 2024-T3 friction stir welded joint", Corrosion Science, 53, 3026, 2011.

[5] LUMSDEN, J. B. , MAHONEY, M. W., POLLOCK, G., et al., "Intergranular Corrosion Following Friction Stir Welding of Aluminum Alloy 7075-T651", Corrosion, 55, 1127,1999.

[6] PÉREZ, H., TUFARO, L., BERARDO, L., et al., "Comportamiento frente a la corrosión de uniones soldadas por fricción agitación de AA7075-T651", $15^{\circ}$ Congreso internacional de metalurgia y materiales CONAMET/SAM, 2015.

[7] AMERICAN SOCIETY FOR METALS (ASM), ASM Handbook: Properties and Selection: Nonferrous Alloys and Special-Purpose Materials (Vol. 2), ASM International, 2005.

[8] HATCH, J. E., Aluminum: properties and physical metallurgy, ASM International, 1984.

[9] VIANA, F., PINTO, A.M.P., SANTOS, H.M.C., et al., "Retrogression and re-ageing of 7075 aluminium alloy: microstructural characterization" Journal of Materials Processing Technology, 1999, 92-93, 54-59.

[10] PASTOR, A., SVOBODA, H. G., "Time-evolution of Heat Affected Zone (HAZ) of Friction Stir Welds of AA7075-T651", Journal of Materials Physics and Chemistry, 2013, 1, 58-64.

[11] RHODES, C. G., MAHONEY, M. W., BINGEL, W. H., et al., "Effects of friction stir welding on microstructure of 7075 aluminum", Scripta Materialia, v.36, n.69, 1997.

[12] SU, J.Q., NELSON, T. W., STERLING, C. J., "Microstructure evolution during FSW/FSP of high strength aluminum alloys", Materials Science and Engineering: A 405, v.277, 2005.

[13] BIRBILIS, N., BUCHHEIT, R. G., "Electrochemical characteristics of intermetallic phases in aluminum alloys an experimental survey and discussion", Journal of The Electrochemical Society 152, B140 (2005). 